OPEN ACCESS

Edited by:

Qi Yuan,

Memorial University, Canada

Reviewed by:

Matthew Philip Parsons,

University of British Columbia,

Canada

De-Lai Qiu,

Yanbian University, China

Yevgenia Kozorovitskiy,

Northwestern University, USA

${ }^{*}$ Correspondence:

Constance Hammond,

Institut de Neurobiologie de la Méditerranée, Inserm UMR901,

163 Route de Luminy, BP13, 13273 Marseille Cedex 9, France constance.hammond@inserm.fr

Received: 14 January 2015 Accepted: 15 May 2015

Published: 29 May 2015

Citation

Pearlstein E, Gouty-Colomer L-A,

Michel FJ, Cloarec $R$

and Hammond C (2015)

Glutamatergic synaptic currents of nigral dopaminergic neurons follow a postnatal developmental sequence.

Front. Cell. Neurosci. 9:210. doi: 10.3389/fncel.2015.00210

\section{Glutamatergic synaptic currents of nigral dopaminergic neurons follow a postnatal developmental sequence}

\author{
Edouard Pearlstein 1,2, Laurie-Anne Gouty-Colomer ${ }^{1,2}$, François J. Michel1,2, \\ Robin Cloarec ${ }^{1,2}$ and Constance Hammond ${ }^{1,2 *}$
}

${ }^{1}$ UMR 901, Aix-Marseille Université, Marseille, France, ${ }^{2}$ Institut de Neurobiologie de la Méditerranée, Inserm UMR 901, Marseille, France

The spontaneous activity pattern of adult dopaminergic (DA) neurons of the substantia nigra pars compacta (SNc) results from interactions between intrinsic membrane conductances and afferent inputs. In adult SNc DA neurons, low-frequency tonic background activity is generated by intrinsic pacemaker mechanisms, whereas burst generation depends on intact synaptic inputs in particular the glutamatergic ones. Tonic DA release in the striatum during pacemaking is required to maintain motor activity, and burst firing evokes phasic DA release, necessary for cue-dependent learning tasks. However, it is still unknown how the firing properties of SNc DA neurons mature during postnatal development before reaching the adult state. We studied the postnatal developmental profile of spontaneous and evoked AMPA and NMDA ( $N$ Methyl-D-aspartic acid) receptor-mediated excitatory postsynaptic currents (EPSCs) in SNc DA neurons in brain slices from immature (postnatal days P4-P10) and young adult (P30-P50) tyrosine hydroxylase (TH)-green fluorescent protein mice. We found that somato-dendritic fields of SNc DA neurons are already mature at P4-P10. In contrast, spontaneous glutamatergic EPSCs show a developmental sequence. Spontaneous NMDA EPSCs in particular are larger and more frequent in immature SNc DA neurons than in young adult ones and have a bursty pattern. They are mediated by GluN2B and GluN2D subunit-containing NMDA receptors. The latter generate long-lasting, DQP 1105-sensitive, spontaneous EPSCs, which are transiently recorded during this early period. Due to high NMDA activity, immature SNc DA neurons generate large and long lasting NMDA receptor-dependent (APV-sensitive) bursts in response to the stimulation of the subthalamic nucleus. We conclude that the transient high NMDA activity allows calcium influx into the dendrites of developing SNc DA neurons.

Keywords: substantia nigra, dopaminergic neurons, development, AMPA receptors, NMDA receptors, EPSC, NR2D subunit, patch clamp

\section{Introduction}

The dopaminergic (DA) neurons of the substantia nigra pars compacta (SNc, A9) are involved in the control of reward-related behavior and motor performances (Schultz, 2013). The spontaneous activity pattern of adult SNc DA neurons results from the interactions between intrinsic and synaptic currents. In adult rodents in vivo, this varies between a slow, intrinsically generated, 
pacemaker-like firing pattern and an irregular pattern with bursts triggered by the transient interaction between ionotropic glutamate receptors and voltage gated ionic channels (Bunney et al., 1973; Grace and Bunney, 1984a,b; Grace and Onn, 1989; Hyland et al., 2002; Fa et al., 2003; Deister et al., 2009). In vitro, only the pacemaker-like pattern is observed (Grace and Onn, 1989; Yung et al., 1991; Richards et al., 1997; Gulacsi et al., 2003; Paladini and Roeper, 2014), except in slices from juvenile (P15P21) rats, where a small proportion of SNc neurons show bursting activity in vitro (Mereu et al., 1997).

The firing rate and firing pattern of SNc neurons are major determinants of the levels of dopamine released from terminals. The robustness of pacemaking underlies its biological importance in delivering a constant basal level of DA in target basal ganglia nuclei such as the striatum, to provide a general motivating function (Wise, 2004). In contrast, burst firing greatly and transiently increases dopamine release (Gonon, 1988; Manley et al., 1992; Chergui et al., 1994; Grillner and Mercuri, 2002), which in turn promotes the corticostriatal plasticity necessary for habit-learning (Reynolds and Wickens, 2000; Centonze et al., 2001; Calabresi et al., 2007; Kreitzer and Malenka, 2008; Schultz, 2013).

Interaction between glutamatergic afferents and ionotropic glutamate receptors play a major role in the generation of bursts in adult SNc DA neurons. Dendritic application of glutamate or NMDA ( $N$-Methyl-D-aspartic acid) in vitro or stimulation of afferents at $50-100 \mathrm{~Hz}$ (but not $10 \mathrm{~Hz}$ ) in the continuous presence of $\mathrm{GABA}_{\mathrm{A}}, \mathrm{GABA}_{\mathrm{B}}$, and $\mathrm{D}_{2}$ receptor antagonists, generate in vivo-like burst firing (Grace and Bunney, 1983; Johnson et al., 1992; Smith and Grace, 1992; Chergui et al., 1993; Christoffersen and Meltzer, 1995; Meltzer et al., 1997; Blythe et al., 2007, 2009; Wang et al., 2011). Furthermore, SNc DA bursts triggered by electrical stimulation of glutamatergic afferents or iontophoretic application of glutamate/aspartate in brain slices are blocked by NMDA receptor antagonists (Deister et al., 2009). Accordingly, genetic inactivation of NMDA receptors selectively in SNc DA neurons impairs spontaneous and evoked burst firing without affecting pacemaker-like activity (Zweifel et al., 2009). In juvenile rats, both AMPA ( $\alpha$-amino-3-hydroxy5-methyl-4-isoxazolepropionic acid) and NMDA receptors are critical for transient burst-like, high-frequency firing (Blythe et al., 2007). Juvenile (P7-P28) rodent SNc neurons express AMPA-evoked currents mediated by GluA2-containing AMPA receptors, kainate (KA)-evoked currents mediated by GluK3 and GluK5-containing KA receptors and NMDA-evoked currents mediated by GluN2B- and GluN2D-containing (but not GluN2A-containing) NMDA receptors (Mereu et al., 1991; Bischoff et al., 1997; Gotz et al., 1997; Wullner et al., 1997; Counihan et al., 1998; Chatha et al., 2000; Lin and Lipski, 2001; Vivo et al., 2002; Jones and Gibb, 2005; Brothwell et al., 2008; Suarez et al., 2010). AMPA and NMDA receptors are selectively localized to a subpopulation of asymmetric synapses in the adult $\mathrm{SNc}$ and the two receptor types, at least partially, co-localize at individual synapses (Chatha et al., 2000).

Glutamatergic afferents to SNc neurons mainly originate in the subthalamic (STN) and pedunculopontine (PPN) nuclei. STN and PPN axons form asymmetric synapses on medium-sized and small SNc dendrites. The PPN boutons tend to form synapses onto larger diameter dendrites than the STN boutons (Hammond et al., 1978; Jackson and Crossman, 1983; Scarnati et al., 1984; Rye et al., 1987; Rinvik and Ottersen, 1993; Futami et al., 1995; Takakusaki et al., 1996).

Since AMPA and NMDA receptor activation generates transient high-frequency activity in SNc DA neurons, plasticity in their number, distribution and/or subunit composition during development could modify excitatory synaptic integration in SNc DA neurons, and thus their activity pattern later in adulthood. We therefore investigated the postnatal development of synaptic AMPA and NMDA receptor-mediated currents and how they influence the ability of SNc neurons to generate bursts in response to STN stimulation.

\section{Materials and Methods}

All experiments were approved by the Institut National de la Santé et de la Recherche Médicale (INSERM) animal care and use agreement (D-13-055-19) and the European Community Council Directive (2010/63/UE). Animals had access to food and water ad libitum and were housed in our institutional animal facilities under a $12 \mathrm{~h} \mathrm{light/dark} \mathrm{cycle} \mathrm{at} 22-24^{\circ} \mathrm{C}$.

\section{Mice}

We used mice expressing the green fluorescent protein (GFP) under the control of the promoter of tyrosine hydroxylase (TH-GFP mice). TH-GFP mice (C57BL/6 strain; Matsushita et al., 2002) were initially backcrossed on a 129 sv background and then interbred with wild-type $129 \mathrm{sv}$ mice to generate the study population of heterozygous TH-GFP mice. At P2P5, TH-GFP pups were easily differentiated via a UV lamp from wild-type pups, because they have a fluorescent navel. Immunocytochemistry for TH in nigral slices from THGFP mice showed that only $4 \%$ of GFP-positive SNc neurons were $\mathrm{TH}$ negative (Supplementary Figure S1).

\section{Slice Preparation}

Mice of either sex were killed at age P4-P10 and P30-P50 (P30+) by decapitation under halothane anesthesia. Coronal or sagittal slices (400 $\mu \mathrm{m}$ thick) were cut in ice-cold oxygenated solution containing (in $\mathrm{mM}$ ): 110 choline, $2.5 \mathrm{KCl}, 1.25 \mathrm{NaH}_{2} \mathrm{PO}_{4}, 7$ $\mathrm{MgCl}_{2}, 0.5 \mathrm{CaCl}_{2}, 25 \mathrm{NaHCO}_{3}$, seven glucose. During the recovery period, slices were placed at room temperature in standard artificial CSF (ACSF) saturated with 95\% $\mathrm{O}_{2} / 5 \% \mathrm{CO}_{2}$ and containing (in mM): $126 \mathrm{NaCl}, 3.5 \mathrm{KCl}, 1.2 \mathrm{NaH}_{2} \mathrm{PO}_{4}, 1.3$ $\mathrm{MgCl}_{2}, 2 \mathrm{CaCl}_{2}, 25 \mathrm{NaHCO}_{3}, 11$ glucose.

\section{Electrophysiology}

We recorded the activity of SNc TH-GFP neurons in the SNc dorsal to $\mathrm{SN}$ reticulate. We used two groups of mice: immature (P4-P10) and young adults (P30-P50). All recordings were made at $32^{\circ} \mathrm{C}$. Cells were visualized with infrared-differential interference optics (Axioskop2, Zeiss). For whole-cell voltageclamp recordings of AMPA EPSCs and spikes, the pipette 
(6-10 M $\Omega$ ) contained (in $\mathrm{mM}$ ): $128.5 \mathrm{~K}$-gluconate, $11.5 \mathrm{KCl}$, $1 \mathrm{CaCl}_{2}, 10$ EGTA, 10 HEPES, $2.5 \mathrm{MgATP}, 0.3 \mathrm{NaGTP}, \mathrm{pH}$ 7.32, 280 mOsm and for the recording of NMDA EPSCs, the pipette contained (in $\mathrm{mM}$ ): $120 \mathrm{Cs}$-gluconate, $13 \mathrm{CsCl}$, $1 \mathrm{CaCl}_{2}, 10$ HEPES, 10 EGTA, pH 7.2-7.4, 275-285 mOsm. Biocytin (Sigma, $5 \mathrm{mg} / \mathrm{ml}$ ) was added to the pipette solution and osmolarity was corrected when necessary. We performed patchclamp recordings in whole-cell configuration using the Digidata 1344A interface, the Multiclamp 700 A amplifier, and PClamp8 software (Molecular Devices). Access resistance ranged between 10 and $30 \mathrm{M} \Omega$, and the results were discarded if access resistance changed by $>20 \%$. Since $4 \%$ of GFP-positive SNc neurons appeared to be TH-negative, we identified SNc DA according to several criteria. During recordings we identified them from their location at the dorsal edge of SN, their GFP fluorescence and their typical electrophysiological characteristics (in K gluconate recordings), i.e., action potentials of long duration ( $>2 \mathrm{~ms}$ ) and a pronounced sag in response to hyperpolarizing steps. After recordings we checked the location of the recorded neurons in the SNc and their morphological characteristics (see Cell Labeling and $\mathrm{TH}$ Immunocytochemistry). We measured Ih amplitude by subtracting the amplitude of the current at the end of the $800 \mathrm{~ms}$ hyperpolarizing step to $-140 \mathrm{mV}\left(V_{\mathrm{H}}=-60 \mathrm{mV}\right)$ from the amplitude of the current $15 \mathrm{~ms}$ after the first capacitative current.

We measured spontaneous AMPA/KA currents in voltageclamp mode at $V_{\mathrm{H}}=-60 \mathrm{mV}$ in the continuous presence of Gabazine $(5 \mu \mathrm{M})$ to block $\mathrm{GABA}_{\mathrm{A}}$ receptors. We measured spontaneous NMDA currents in voltage-clamp mode at $V_{\mathrm{H}}=+40 \mathrm{mV}$ in the continuous presence of Gabazine (5 $\mu \mathrm{M})$ and NBQX (2,3-dihydroxy-6-nitro-7-sulfamoyl-benzo (f)quinoxaline-2,3-dione, $10 \mu \mathrm{M}$ ) to block $\mathrm{GABA}_{\mathrm{A}}$ and AMPA/KA receptors, respectively. These currents were stored on a computer using Pclamp8 software (Molecular Devices) and analyzed off-line with Mini Analysis software (Synaptosoft 6.0 ), to determine the inter-event intervals (IEIs), amplitude, rise time, and decay time of spontaneous currents. The decay of spontaneous synaptic currents was well fitted by a singleexponential function, starting at the peak of the current to the time point when the current had decayed to $99.9 \%$ of its peak amplitude. All detected currents were then visually inspected to reject artifactual events. To quantify the respective contribution of AMPA receptors and KA receptors to synaptic transmission, we performed experiments in the presence of $1 \mu \mathrm{M}$ NBQX at a dose which preferentially antagonizes AMPA receptors. NMDA spontaneous EPSCs (sEPSCs) occurred either as single events or in bursts. We defined a burst of NMDA sEPSCs as the occurrence of at least three superimposed NMDA sEPSCs and a bursty pattern as at least two bursts/cell/3 min. Miniature AMPA or NMDA currents, recorded in the presence of TTX $(1 \mu \mathrm{M})$, were not studied because they had an extremely low frequency at all ages tested.

\section{STN Stimulation}

We performed stimulation of the STN and whole-cell recordings of glutamatergic post-synaptic responses (EPSPs and spikes) from SNc DA neurons in current clamp mode, in medial sagittal slices, where projections from STN to SNc neurons are functional (Falkenburger et al., 2001). We delivered rectangular pulses of fixed duration (200 $\mu \mathrm{s})$ and 100-600 $\mu \mathrm{A}$ amplitude at a frequency of $0.01-50 \mathrm{~Hz}$ (Grass stimulator) between the two poles of an electrode made from twisted Formvar insulated nichrom wires (66 $\mu \mathrm{m}$ diameter each, A-M Systems) positioned in the middle of the STN (only the very tips of the wires were not insulated). Postsynaptic responses evoked in SNc DA neurons by high frequency $(50 \mathrm{~Hz})$ stimulation of the STN in the continuous presence of gabazine $(5 \mu \mathrm{M})$ were defined as bursts of spikes when they consisted of a depolarization giving rise to a train of action potentials that outlasted the depolarizing step. The duration of spikes (half width) was measured at half maximal amplitude.

\section{Drugs}

Drugs were prepared as concentrated stock solutions and diluted in ACSF for bath application: gabazine, a $\mathrm{GABA}_{\mathrm{A}}$ receptor antagonist, and APV (D-(-)-2-amino-5-phosphonopentanoic acid), an NMDA receptor antagonist and tetrodotoxin (TTX) a blocker of voltage-gated $\mathrm{Na}^{+}$channels were purchased from Sigma. NBQX, an AMPA/KA receptor antagonist and was donated by the National Institute of Mental Health, NIMH chemical synthesis and drug supply program. DQP 1105 [5-(4-Bromophenyl)-3-(1,2-dihydro-6-methyl-2-oxo-4-phenyl3-quinolinyl)-4,5-dihydro-g-oxo-1H-pyrazole-1-butanoic acid] $(10 \mu \mathrm{M})$, a non-competitive NMDA receptor antagonist which displays over 50-fold selectivity for GluN2D- and GluN2Ccontaining receptors over GluN2B- containing receptors, and Ro 25-6981 maleate ( $\alpha \mathrm{R}, \beta S)-\alpha-(4-H y d r o x y p h e n y l)-\beta$-methyl4-(phenylmethyl)-1-piperidinepropanol maleate) (1 $\mu \mathrm{M})$, a selective activity-dependent blocker of NMDA receptors containing the GluN2B subunit, were both purchased from Tocris.

\section{Cell Labeling and TH Immunocytochemistry}

After the recording session, to localize and analyze the recorded SNc DA neurons, we visualized the biocytin-injected neurons. After $24 \mathrm{~h}$ in paraformaldehyde $(3 \%)$ at $4^{\circ} \mathrm{C}$, the sections were rinsed in PBS and preincubated for $1 \mathrm{~h}$ in $0.3 \%$ Triton X-100 (Abcys) in PBS with 5\% normal goat serum (NGS) at room temperature. Slices were then incubated in Streptavidin-Cy3 (1:500) in PBS-Triton X-100 (0.3\%) and NGS $(5 \%)$ for $12 \mathrm{~h}$ at $4^{\circ} \mathrm{C}$. After thorough rinsing, slices were mounted in Fluoromount and coverslipped. Confocal Images were taken with a Leica SP5-X (objective $\times 40$, $\mathrm{NA}=1.3$ ) and stacks were filtered (median 3D) and stitched (3D stitching) with FIJI software (ImageJA v1.46b, Open source software, http://pacific.mpi-cbg.de). Dendritic and axonal arbors were reconstructed for morphological analysis using the Neurolucida system (MicroBrightField Inc.). To check whether GFP expression was restricted to TH-positive neurons of the $\mathrm{SNc}$, slices were incubated in anti-TH polyclonal antibody (PelFreez, dilution of 1:1000) for $12 \mathrm{~h}$. After rinsing with PBS, slices were incubated in anti-rabbit IgG secondary antibody Alexa A555 (Life Technologies, dilution of 1:500) for $1 \mathrm{~h}$. To count THpositive and GFP-positive neurons, images were taken with a 
Zeiss observer Z1 microscope with Apotome device (structured illumination), $20 \times$ magnification.

\section{Statistics}

Results are given in the text and figures in the form of mean \pm SEM. Non-parametric Mann-Whitney test (Graphpad Prism 5 software, San Diego, CA, USA) was used to compare results from $\mathrm{P} 4-\mathrm{P} 10$ and $\mathrm{P} 30+\mathrm{SNc}$ DA neurons. Since there was no significant difference between the full set of results obtained at P4-P5 and at P8-P10 for AMPA- and NMDA-mediated sEPSCs (data not shown), we pooled the results obtained between P4 and P10. For example, there was no significant difference for the frequency $(P=0.3)$, and amplitude $(P=0.5)$ of AMPA sEPSCs. Similarly, there was no significant difference for the frequency $(P=0.35)$, amplitude $(P=0.52)$ of single NMDA sEPSCs, nor for the characteristics of bursts of NMDA sEPSCs: burst frequency $(P=0.34)$, burst duration involving at least three events $(P=0.15)$, and mean intraburst frequency $(P=0.15)$. A non-parametric two-tailed paired $t$-test was used to compare values obtained at aiven age before and during drug application. Kolmogorov-Smirnov test was used to compare cumulative distributions. For each test performed the $\mathrm{P}$ value was provided and the statistical significance was taken at $P \leq 0.05$.

\section{Results}

\section{Developmental Characteristics of Dendritic Field and Intrinsic Membrane Properties of SNc DA Neurons}

The dendritic field of SNc DA neurons did not significantly change between P4-P10 $(n=13)$ and P30+ $(n=9)$ (Figure 1). The mean number of dendritic trunks was $4 \pm 1$ at P4-P10 and $4 \pm 1$ at $\mathrm{P} 30+(P=0.7)$, the mean number of dendritic ends was $13 \pm 1$ at $\mathrm{P} 4-\mathrm{P} 10$ and $12 \pm 1$ at $\mathrm{P} 30+(P=0.6)$, the mean total dendritic length was $1386 \pm 202 \mu \mathrm{m}$ at P4-P10 and $1522 \pm 249$ at $\mathrm{P} 30+(P=0.6)$ and the mean dendritic volume was $2.6 \times 10^{6} \pm 0.7 \times 10^{6}{\mu \mathrm{m}^{3}}$ at P4-P10 and $5.7 \times 10^{6} \pm 1.7 \times 10^{6}$ at P30 $(P=0.1)$. The axon originated either from the soma ( $n=5 / 13$ at $\mathrm{P} 4-\mathrm{P} 10 ; n=2 / 9$ at $\mathrm{P} 30+$ ) or from a primary dendritic trunk ( $n=8 / 13$ at $\mathrm{P} 4-\mathrm{P} 10 ; n=7 / 9$ at $\mathrm{P} 30+$ ), as already described for P15-P20 SNc DA neurons (Hausser et al., 1995; Gentet and Williams, 2007; Blythe et al., 2009).

The mean membrane resistance of P4-P10 neurons was twice as high $(468.8 \pm 54.5 \mathrm{M} \Omega, n=38)$ as that of P30+ neurons $(230.7 \pm 18.1 \mathrm{M} \Omega, n=22, P=0.0002)$, but their mean membrane capacitance was similar for the two age groups $(30.9 \pm 2.9 \mathrm{pF}$ and $32.3 \pm 2.9 \mathrm{pF}$, respectively, $P=0.58)$. The amplitude of the inwardly rectifying $\mathrm{H}$ current $\left(I_{\mathrm{h}}\right)$ in response to hyperpolarizing pulses to $-140 \mathrm{mV}\left(V_{\mathrm{H}}=-60 \mathrm{mV}\right)$, was similar at P4-P10 $(-327.3 \pm 34.7 \mathrm{pA}, n=32)$ to that at P30+ $(-272.3 \pm 31.5 \mathrm{pA}, n=11, P=0.57)$.

\section{AMPA Receptor-Mediated sEPSCs Follow a Postnatal Developmental Sequence}

We recorded sEPSCs $\left(V_{\mathrm{H}}=-60 \mathrm{mV}\right)$ at $\mathrm{P} 4-\mathrm{P} 10$ and at $\mathrm{P} 30+$ that were insensitive to APV $(40 \mu \mathrm{M})$, the specific antagonist

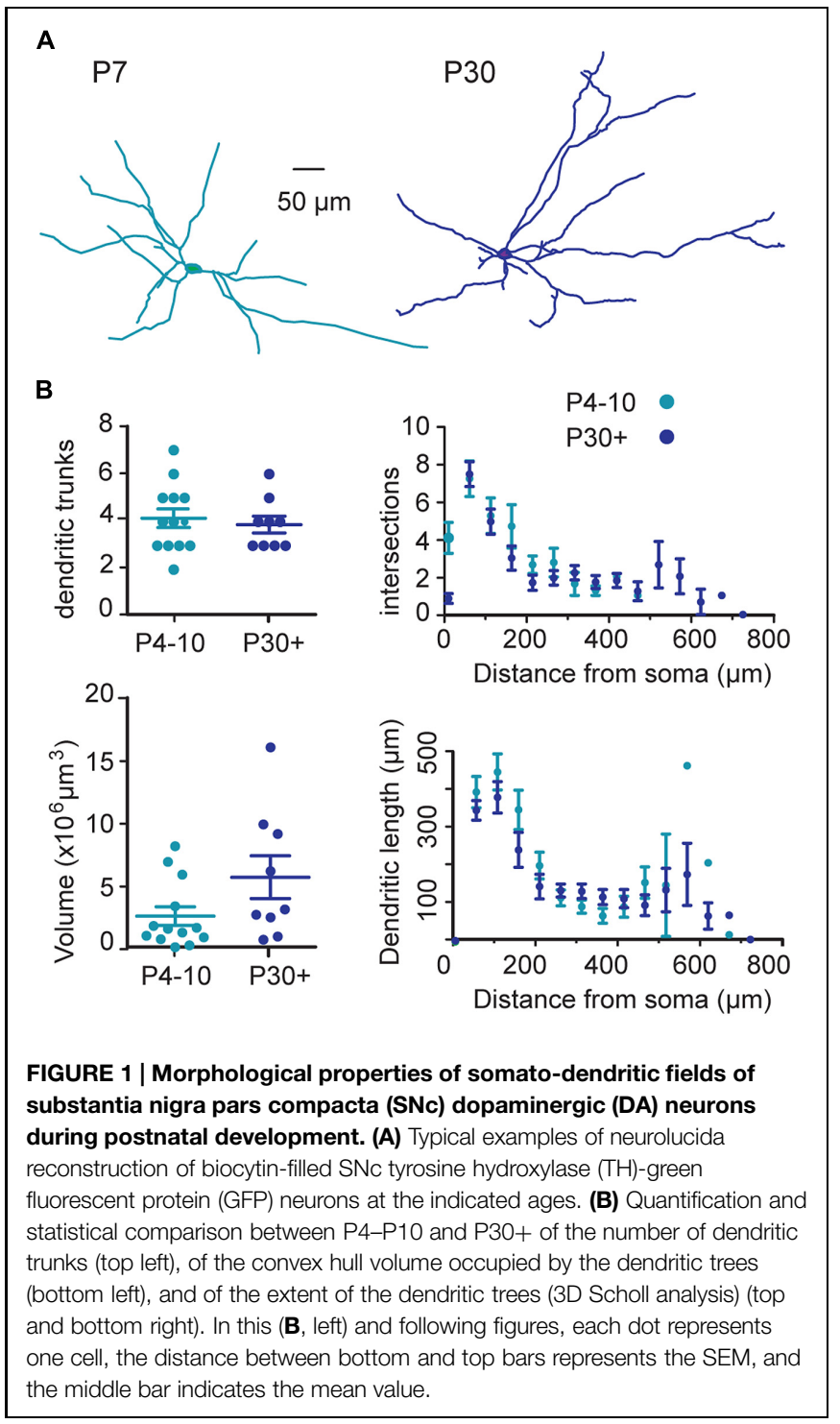

of NMDA receptors, but fully blocked by the addition of NBQX $1 \mu \mathrm{M}$, a preferential antagonist of AMPA receptors $(n=6$, data not shown). Application of $1 \mu \mathrm{M}$ NBQX specifically blocked the AMPA receptor-mediated current and allowed the measurement of the KA receptor-mediated current. In this condition, we demonstrated that neither immature nor young adult SNc neurons generate spontaneous KA-receptor-mediated EPSCs.

AMPA receptor-mediated sEPSCs (AMPA sEPSCs) had larger amplitudes $(P=0.017)$ and longer IEIs $(P=0.005)$ in immature than in young adult SNc DA neurons. The mean amplitude and mean IEI were $16.0 \pm 1.9 \mathrm{pA}$ and $4.4 \pm 0.7 \mathrm{~s}$ in P4-P10 SNc neurons $(n=24)$ and $11.8 \pm 1.0 \mathrm{pA}$ and $2.1 \pm 0.4 \mathrm{~s}$ in $\mathrm{P} 30+\mathrm{SNc}$ neurons $(n=19$; Figures $2 \mathrm{~A}, \mathbf{B})$. The cumulative frequency distributions for the amplitude or the IEIs of single AMPA EPSCs also differed significantly $(\mathrm{P}=0.018$ and $\mathrm{P}<0.001$, respectively; Kolmogorov-Smirnov test) between the two age groups (Figure 2C). Single AMPA sEPSCs had a similar rise time at P4-P10 and at P30+ $(1.17 \pm 0.08 \mathrm{~ms}, n=24,1.11 \pm 0.09 \mathrm{~ms}$, 
$n=19$, respectively; $P=0.6)$ but had a longer mean decay time at P4-P10 (9.3 $\pm 1.7 \mathrm{~ms})$ than at $\mathrm{P} 30+(6.0 \pm 1.1 \mathrm{~ms}, P<0.0001$; Figure 2D). Similarly, cumulative frequency distributions for the rise time of AMPA-mediated sEPSCs did not differ significantly between $\mathrm{P} 4-\mathrm{P} 10$ and $\mathrm{P} 30+(P>0.99)$, but the decay times were significantly different $(P<0.0001$; Figure 2D). Therefore, AMPA sEPSCs in SNc DA neurons mature between P4-P10 and P30+.

\section{NMDA Receptor-Mediated sEPSCs Follow a Postnatal Developmental Sequence}

At P4-P10, single NMDA sEPSCs showed greater amplitude $(29.3 \pm 2.7 \mathrm{pA})$ and shorter IEIs $(3.6 \pm 0.6 \mathrm{~s}, n=20$ neurons) than at $\mathrm{P} 30+$ (amplitude $20.0 \pm 1.7 \mathrm{pA} ; 6.2 \pm 0.9 \mathrm{~s}$, $n=18 ; P=0.007$ and 0.027 , respectively; Figures $3 \mathbf{A}, \mathbf{B})$. The cumulative frequency distributions for the amplitude or the IEIs of single NMDA sEPSCs differed significantly $(P<0.0001$ for both, Kolmogorov-Smirnov test) between the two age groups (Figure 3C). Single NMDA sEPSCs also showed a longer mean decay time at P4-P10 (92.6 $\pm 3.8 \mathrm{~ms}, n=20)$ than at $\mathrm{P} 30+(75.5 \pm 4.5 \mathrm{~ms}, n=18, P=0.0003)$ but a similar mean rise time $(7.3 \pm 0.2 \mathrm{~ms}$ and $7.6 \pm 0.3 \mathrm{~ms}$, $P=0.44$ ). The cumulative frequency distributions also differed significantly between the two age groups with respect to decay time $(P<0.0001$, Kolmogorov-Smirnov test $)$, but not with respect to rise time $(P=0.9$; Figure $3 D)$. Strikingly, in the P4-P10 group but not in the P30+ one, NMDA sEPSCs often occurred in bursts. The bursty pattern was present in $60 \%$ of P4-P10 $(n=12 / 20)$ versus $11 \%(2 / 18)$ of P30+ SNc DA neurons. Moreover, P4-P10 bursts were more frequent and consisted of more events (mean burst frequency: $0.04 \pm 0.01 \mathrm{~Hz}$; mean burst duration: $416 \pm 91 \mathrm{~ms}$ involving 3-21 events with a mean intraburst frequency of $17.3 \pm 3.1 \mathrm{~Hz} ; n=146$ bursts in 12 neurons) than P30+ bursts (mean burst frequency: $0.02 \pm 0.01 \mathrm{~Hz}$, mean burst duration: $259 \pm 95 \mathrm{~ms}$ involving 3-5 events with a mean intraburst frequency of $19.1 \pm 8.7 \mathrm{~Hz}$, $n=15$ bursts in three neurons; Figure 4). Statistical comparison between the two groups was rendered impossible by the very small number of bursts generated by young adult SNc DA neurons.

\section{Early Bursting NMDA sEPSCs were Mediated by GluN2D-Containing NMDA Receptors}

We investigated whether the developmental shift of NMDA sEPSCs was due to altered NMDA receptor subunit composition. During development SNc neurons express NMDA-evoked currents mediated by GluN2B- and GluN2D-containing (but not GluN2A-containing) NMDA receptors. We first tested DQP 1105 , at a dose $(10 \mu \mathrm{M})$ which preferentially blocks GluN2C/Dcontaining receptors. It decreased the frequency of P4-P10 single NMDA sEPSCs by $56 \%$ (from $0.32 \pm 0.08$ to $0.14 \pm 0.04 \mathrm{~Hz}$, $n=8$ neurons; $P=0.02$ non-parametric paired $t$-test) but had no effect on P30+ single NMDA sEPSCs amplitude $(17.1 \pm 2.3 \mathrm{pA}$ before and $16.1 \pm 1.7 \mathrm{pA}$ during DQP, $n=5 ; P=0.3$ ) or frequency $(0.14 \pm 0.04 \mathrm{~Hz}$ before and $0.19 \pm 0.05 \mathrm{~Hz}$ during DQP, $n=5 ; P=0.2$; Figure 5). DQP 1105 also significantly reduced the occurrence of bursts of P4-P10 NMDA sEPSCs (interburst frequency: $0.07 \pm 0.02 \mathrm{~Hz}$ before and $0.010 \pm 0.002 \mathrm{~Hz}$ during

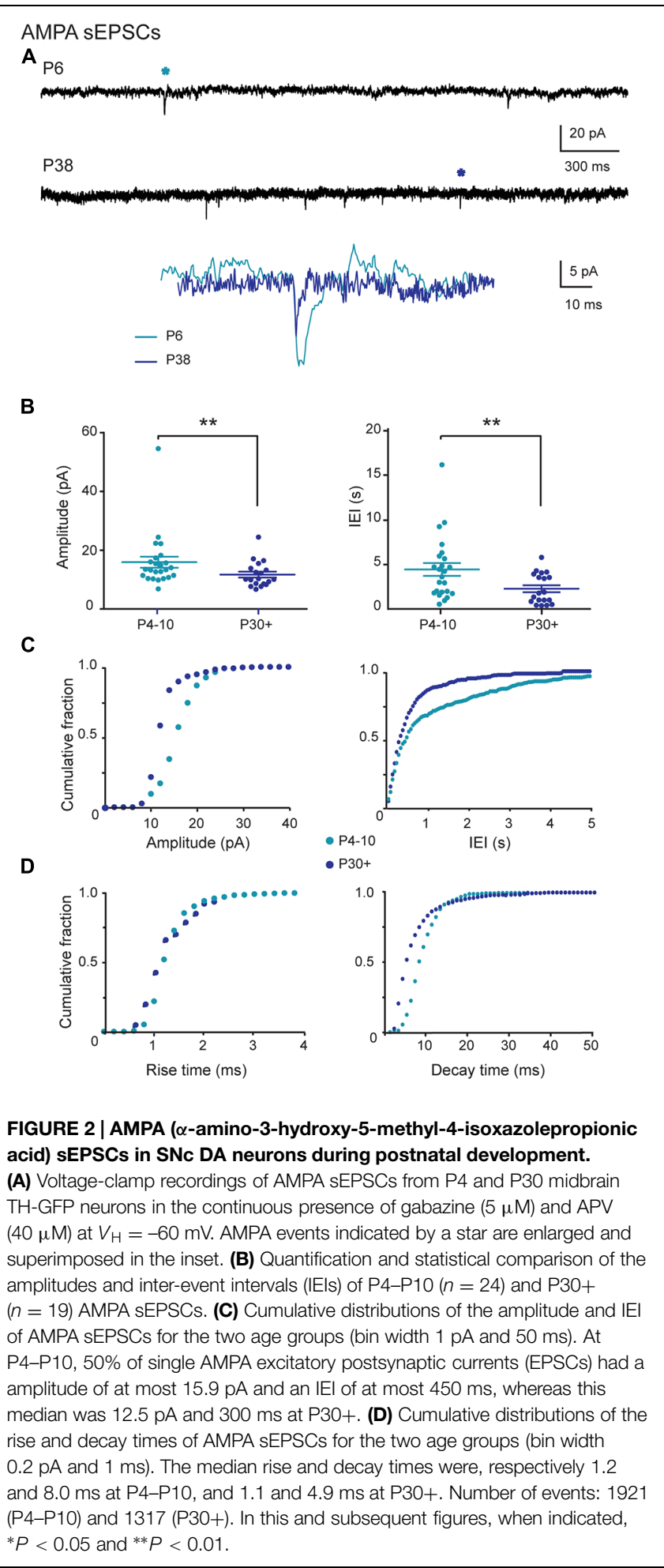

DQP; $P=0.007)$ but did not change either their duration $(550 \pm 137 \mathrm{~ms}$ before and $810 \pm 456 \mathrm{~ms}$ during DQP; $P=0.8)$ or their intraburst frequency $(12.0 \pm 2.6 \mathrm{~Hz}$ before and $14 \pm 3 \mathrm{~Hz}$ during DQP; $P=0.8 ; n=6)$. Subsequent application of Ro 25-6981 (1 $\mu \mathrm{M})$, a preferential blocker of GluN2B-containing 


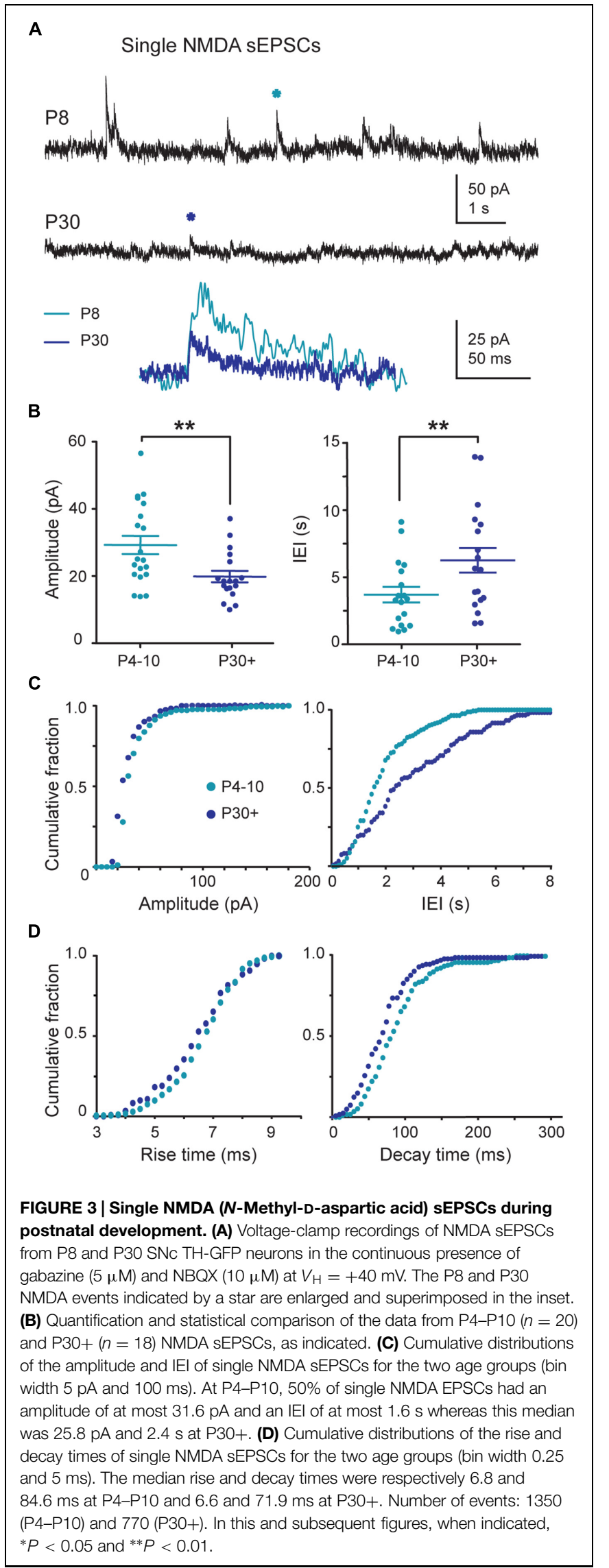

A
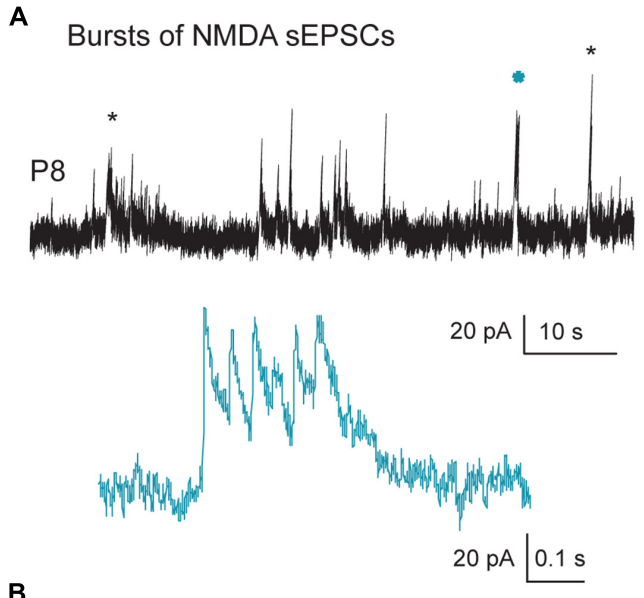

B

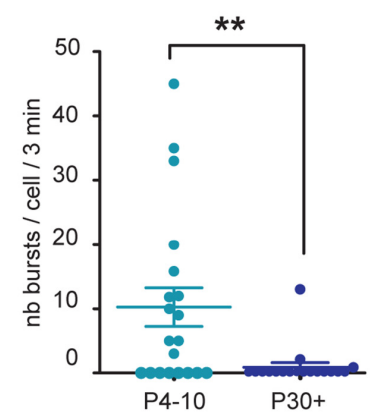

FIGURE 4 | Bursts of NMDA sEPSCs during postnatal development. (A) Voltage-clamp recordings of NMDA sEPSCs from a P8 SNc TH-GFP neuron in the continuous presence of gabazine $(5 \mu \mathrm{M})$ and NBQX $(10 \mu \mathrm{M})$ at $V_{H}=+40 \mathrm{mV}$. The stars (black and blue) indicate bursts of NMDA sEPSCs. The other events are single events either isolated or in trains. The burst indicated by a blue star is shown in the inset at a more rapid time base. (B) Quantification and statistical comparison of the number of bursts per cell per 3 min from P4-P10 and P30+ SNc DA neurons. In this and subsequent figures, when indicated, ${ }^{*} P<0.05$ and ${ }^{* *} P<0.01$.

NMDAR, abolished all single and bursting NMDA sEPSCs, in P4-P10 and P30+ SNc DA neurons (data not shown). Application of Ro 25-6981, before that of DQP 1105, also blocked all ongoing NMDA sEPSCs in both groups, demonstrating that all NMDA receptors contain NR2B subunits.

\section{DQP 1105 had a Postsynaptic Action}

To investigate whether the GluN2D-containing NMDA receptors were localized pre- or postsynaptically, we checked whether DQP $1105(10 \mu \mathrm{M})$ affected the amplitude and frequency of AMPA sEPSCs in P4-P10 SNc neurons. DQP 1105 had no effect on either the mean amplitude $(14.4 \pm 2.6 \mathrm{pA}$ before DQP vs $15.0 \pm 2.9 \mathrm{pA}$ after DQP, $n=5, P=1)$ or the mean frequency $(1.8 \pm 0.8 \mathrm{~Hz}$ before DQP vs $2.1 \pm 0.9 \mathrm{~Hz}$ after DQP, $n=5$, $P=0.19$ ) of AMPA sEPSCs of immature SNc neurons (data not shown). Taken together, our results demonstrate that GluN2Dcontaining NMDA receptors are transiently expressed at P4-P10 in SNc DA neurons and are expressed postsynaptically.

All the above results indicate that a GluN2B subunit is present in NMDARs of both immature and young adult SNc DA neurons 




FIGURE 5 | Pharmacology of single and bursts of NMDA sEPSCs during postnatal development. (A) Voltage-clamp recordings of NMDA sEPSCs from a P5 and a P39 SNc TH-GFP neuron in the continuous presence of gabazine $(5 \mu \mathrm{M})$ and $\operatorname{NBQX}(10 \mu \mathrm{M})$ at $V_{H}=+40 \mathrm{mV}$ in the absence (top) or presence (bottom) of DQP1105 (10 $\mu \mathrm{M})$. (B) From left to int, quantification of the effect of DQP 1105 on the frequency of single subsequent figures, when indicated, ${ }^{*} P<0.05$ and ${ }^{* *} P<0.01$. and is indispensable for the generation of NMDA sEPSCs. In contrast, the GluN2D-containing NMDA receptor follows a developmental sequence responsible for the generation of large and frequent single sEPSCs and bursts of sEPSCs in immature SNc DA neurons. Subsequently, GluN2D subunit-containing NMDA receptor-mediated sEPSCs disappear in young adult SNc DA neurons, probably due to the disappearance of GluN2D subunit-containing receptors.

\section{The AMPA/NMDA Ratio of Glutamatergic Receptor-Mediated EPSCs Follows a Developmental Sequence}

We investigated whether a change in NMDA current during development would be evidenced by a change in AMPA/NMDA ratio. Comparison of the $\mathrm{STN}$-evoked monosynaptic responses at $V_{\mathrm{H}}=-70 \mathrm{mV}$ and $+40 \mathrm{mV}$, before and after bath application of APV $(40 \mu \mathrm{M})$, showed that at $V_{\mathrm{H}}=-70 \mathrm{mV}$ the inward EPSC was purely mediated by AMPAR and at $V_{\mathrm{H}}=+40 \mathrm{mV}$, $100 \mathrm{~ms}$ after its onset, the outward EPSC was purely mediated by NMDAR (not shown). To obtain the AMPA/NMDA ratio, we calculated, in the each recorded neuron, the ratio of the peak amplitude of the STN-evoked inward EPSC at $V_{\mathrm{H}}=-70 \mathrm{mV}$ and of the amplitude of the evoked outward EPSC at $+40 \mathrm{mV}, 100 \mathrm{~ms}$ after the EPSC onset. This gave a lower AMPA/NMDA ratio $(1.6 \pm 0.3, n=13)$ at $\mathrm{P} 4-\mathrm{P} 10$ than at $\mathrm{P} 30+(10.5 \pm 2.8, n=11$, $P=0.0001)$. Therefore, NMDA currents largely predominate in P4-P10 SNc DA neurons, in contrast to P30+ (Figure 6).

\section{STN-Evoked Burst Firing of SNc DA Neurons Follows a Developmental Sequence}

We stimulated STN neurons at $50 \mathrm{~Hz}$ (1 s duration) in sagittal slices to study the ability of SNc DA neurons to generate bursts of action potentials (Blythe et al., 2007; Hage and Khaliq, 2015).

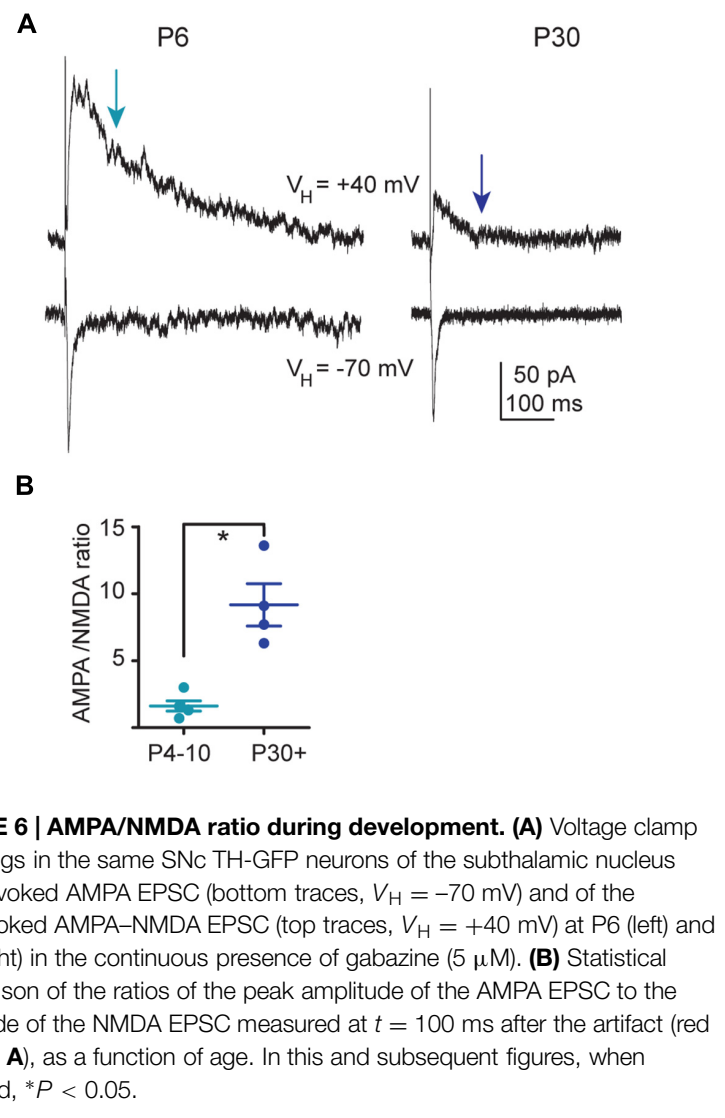

In the continuous presence of $\mathrm{GABA}_{\mathrm{A}}$ receptor antagonists, STN stimulation evoked long-lasting bursts of spikes in juvenile $\mathrm{SNc}$ DA neurons but not in young adult ones. At P4-P10, before 
stimulation, control spike frequency was $1.58 \pm 0.46 \mathrm{~Hz}\left(V_{\mathrm{m}}=-\right.$ $42.2 \pm 1.3 \mathrm{mV})$. The $50 \mathrm{~Hz}$ STN stimulation depolarized the membrane by $30 \%$ (of $12.6 \pm 2.6 \mathrm{mV}$, measured at the end of the $1 \mathrm{~s}$ stimulation), and generated spikes at $16.7 \pm 1.7 \mathrm{~Hz}$ ( $n=16$; Figures $7 \mathbf{A}-\mathbf{C}$ ). At the end of the $1 \mathrm{~s}$ stimulation the amplitude of the evoked action potentials was $33 \%$ smaller than that of the first spike in the train (from $63.3 \pm 2.4$ to $40.4 \pm 3.6 \mathrm{mV}, P=0.0006)$ and their half-width $76 \%$ greater (from $3.4 \pm 0.3$ to $6.2 \pm 0.7 \mathrm{~ms}, P<0.0001$; Figures 7A,E). The STN-evoked depolarization was followed by an afterdepolarization which outlasted the 1 s stimulation period by $623 \pm 174 \mathrm{~ms}$ and generated spikes at $5.1 \pm 1.6 \mathrm{~Hz}(n=12 / 16$; Figure 7A). Bath application of DQP $(10 \mu \mathrm{M})$ had no significant effect on the depolarization amplitude of the evoked burst ( $n=7, P>0.99$; Figure 7D), nor on spike frequency during the stimulation $(P=0.7)$ or during the after- depolarization $(P=0.8)$. Subsequent application of APV $(40 \mu \mathrm{M})$ reduced the amplitude of the STN-evoked depolarization by $78 \%$ (from $11.5 \pm 1.9$ to $2.0 \pm 0.8 \mathrm{mV}$, measured at the end of the stimulation period, $P=0.001)$, reduced spike frequency during the stimulation by $66 \%(P=0.02)$ and totally abolished the after-depolarization. Subsequent application of NBQX $(10 \mu \mathrm{M})$ totally abolished the APV-insensitive depolarization (Figure 7D). At $\mathrm{P} 30+\left(V_{\mathrm{m}}=-45.2 \pm 1.4 \mathrm{mV}\right)$, the spike frequency before stimulation was $0.97 \pm 0.17 \mathrm{~Hz}$ (not significantly different from that at P4-P10, $P=0.21$ ). The $50 \mathrm{~Hz}$ STN stimulation depolarized the membrane by only $9 \%(3.9 \pm 1.7 \mathrm{mV})$ and generated spikes at $10.1 \pm 1.6 \mathrm{~Hz}$ (Figures 7A,B). The evoked depolarization never outlasted the $1 \mathrm{~s}$ stimulation $(n=14 / 14)$. All the above results suggest that STN stimulation evoked a larger NMDA-dependent depolarization at P4-P10 than at $\mathrm{P} 30+$ $(P=0.007)$, with a longer duration due to the presence of afterdepolarization, as well as evoking spikes at a higher frequency at $\mathrm{P} 4-\mathrm{P} 10$ than at $\mathrm{P} 30+(P=0.005)$.

\section{Discussion}

We show here that spontaneous AMPAR-mediated and NMDAR-mediated currents generated by SNc DA neurons mature over the first postnatal month. In particular, NMDA sEPSCs follow a characteristic developmental sequence. In immature compared to mature SNc neurons, NMDA sEPSCs have a greater amplitude and frequency, coupled with a characteristic bursty pattern, correlated with the transient expression of the slowly decaying, DQP 1105-sensitive, sEPSCs mediated by GluN2D subunit-containing NMDA receptors. STN-evoked bursts of spikes were also much larger in immature $\mathrm{SNc}$ DA neurons due to the presence of a high NMDARmediated component. This high NMDA activity of immature SNc DA neurons may allow the integration of synaptic inputs over longer periods, with larger calcium influxes into developing dendrites.

The dendritic tree of SNc DA neurons is already mature just after birth. In our earlier study, we found that midbrain DA neurons at late embryonic (E16-E18) and perinatal (P0P1) stages (Ferrari et al., 2012) extend long axons that already reach the striatum at embryonic day E16, before developing their dendritic tree. Then the dendritic tree progressively matures from E16 (90 $\pm 31 \mu \mathrm{m}$ total dendritic length; $1.5 \pm 0.4$ ends; $n=13)$ to $\mathrm{P} 0(1031 \pm 287 \mu \mathrm{m} ; 12 \pm 3 ; n=6, P=0.0001)$. When dendritic trees at P0 (Ferrari et al., 2012) were compared with dendritic trees at P4-P10 (the present study), no further maturation of dendritic length was observed ( $P=0.09$ MannWhitney test; compare Figure 1A in Ferrari et al., 2012 and Figure 1B). In conclusion, our results suggest that maturation of the morphological properties of the SNc DA neurons occurs during the very early prenatal period, also in agreement with previous results in the rat, where the morphology of TH positive neurons at P1 appears essentially the same as in adults (Tepper et al., 1994; Park et al., 2000).

The absence of spontaneous KAR-mediated currents in young and juvenile SNc DA neurons found here, contrasts with the large inward current previously evoked in outside-out patches of P10-P15 SNc DA neurons by bath application of KA (1 mM; Gotz et al., 1997). This suggests that the GluK1 (GluR5), GluK3 (GluR7), and GluK5 (KA2) receptor subtypes identified in rodent SNc (Bischoff et al., 1997; Wullner et al., 1997) are not activated by spontaneous release of glutamate in slices.

AMPA sEPSCs mature during the first postnatal month and display larger amplitudes in immature than in young adult SNc DA neurons. AMPAR expressed in juvenile SNc DA neurons are mainly GluA2-containing (calcium impermeable) receptors as shown by the $\mathrm{I}-\mathrm{V}$ relationships in $\mathrm{Na}^{+}-$or $\mathrm{Ca}^{2+}$-enriched extracellular media (Gotz et al., 1997). Therefore synaptic activation of AMPAR is not expected to produce $\mathrm{Ca}^{2+}$ inflow in SNc DA neurons.

The major change during the first postnatal month concerns NMDA activity. The striking characteristic is the high spontaneous NMDA activity at P4-P10, as evidenced by large and frequent single NMDA events, sometimes with a bursty pattern, and the large APV-sensitive bursts of spikes evoked in immature but not in young adult SNc DA neurons by STN stimulation.

The spontaneous NMDA EPSCs are recorded in coronal slices where the somas of STN or PPN neurons that send glutamatergic projections to $\mathrm{SNc} \mathrm{DA}$ neurons are absent. The only glutamatergic neurons [positive for the vesicular glutamate transporter type 2 (VGLuT2) mRNA] present in nigral coronal slices and that may send projections to $\mathrm{SNc}$ DA neurons are those described in $\mathrm{SNc}$ (A9) and the ventral tegmental area (VTA, A10). In contrast to VTA neurons which co-express VGluT2 mRNA and $\mathrm{TH}$ in a subgroup of neurons, the VGluT2 neurons in the SNc lack TH (Yamaguchi et al., 2007, 2011, 2013). This suggests that SNc and/or VTA glutamatergic neurons may connect to SNc DA neurons. Bursts of NMDA sEPSCs are likely to result from the summation of the slowly decaying NMDA sEPSCs generated by the transiently expressed, DQP 1105-sensitive, GluN2D-containing NMDA receptors (Dunah et al., 1998; Acker et al., 2011). GluN2D mRNA and protein, but not GluN2C, are preferentially expressed in the mesencephalon (Brothwell et al., 2008). Therefore the DQPsensitive NMDA sEPSCs recorded here were mainly mediated by GluN2D subunit-containing NMDA receptors which have 

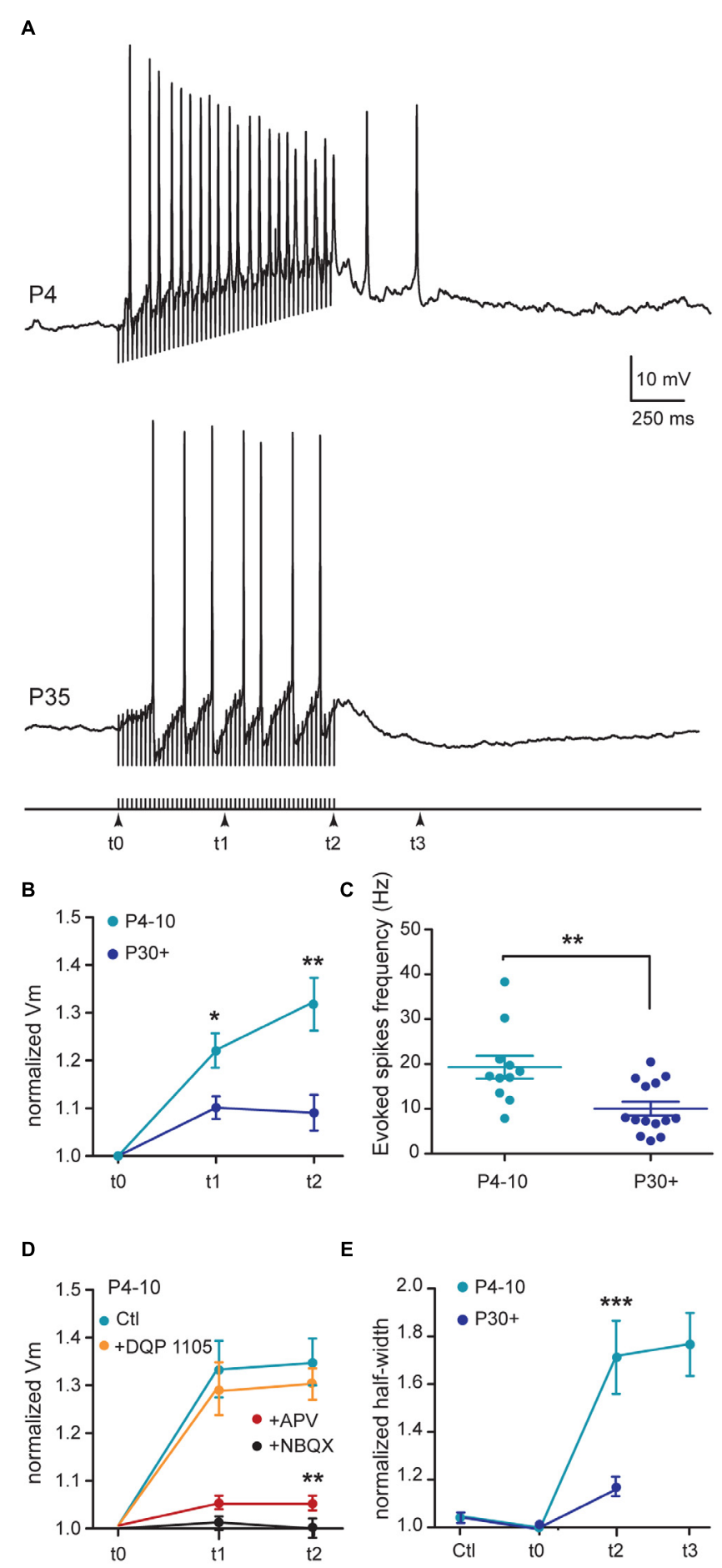

E



FIGURE 7|Subthalamic nucleus-evoked responses of SNc DA neurons during development. (A) Typical examples of current clamp recordings $\left(V_{m}=-43 /-45 \mathrm{mV}\right)$ of responses of SNc DA neurons to $1 \mathrm{~s}$ STN stimulation $(200 \mu \mathrm{s}$ stimuli at $50 \mathrm{~Hz}$ ) in the continuous presence of gabazine $(5 \mu \mathrm{M})$, at the indicated ages. (B) Quantification and statistical comparison of the percent of membrane depolarization (\% $\left.\Delta V_{\mathrm{m}}\right)$ measured at three different times during the $50 \mathrm{~Hz}$ stimulation as indicated in (A) bottom, in P4-P10 and P30+ neurons. (C) Spike frequency during the stimulation period. (D) Normalized membrane depolarization $\left(V_{\mathrm{m}}\right)$ measured at three different times during the $50 \mathrm{~Hz}$ stimulation in the absence (control) and in the presence of cumulative

applications of NMDAR and AMPAR blockers, as indicated (P4-P10 SNc DA neurons). (E) Half-width of the spike just before STN stimulation (tCtl), of the last spike evoked during the stimulation period (t2) and of the last spike evoked during the after-depolarization (t3), normalized to the half-width of the first spike at the onset of the stimulation period (t0). Spikes at t3 are absent from P30+ recordings due to the absence of after-depolarization at that age. The stars in (B,C,E), indicate the statistical results between P4-P10 and P30+. The stars in (D) indicate the statistical results between control (Ctl) and APV, for the same age group (P4-P10). In this and subsequent figures, when indicated, ${ }^{*} P<0.05$, ${ }^{* *} P<0.01$, and ${ }^{* * *} P<0.001$. 
the slowest decay time. The deactivation time constant for the macroscopic current mediated by GluN1/GluN2D assemblies is 6-10 times slower than GluN1/GluN2B (Monyer et al., 1994; Vicini et al., 1998; Wyllie et al., 1998). This characteristic allows the summation of NMDA sEPSCs and the generation of bursts of sEPSCs. We propose that at P4-P10, NMDA sEPSCs result from the activation of diheteromeric GluN1/GluN2B receptors, together with triheteromeric GluN1/GluN2B/GluN2D receptors, (as already described in P14-P20 SNc DA neurons with exogenous NMDA application (Dunah et al., 1998; Jones and Gibb, 2005; Brothwell et al., 2008; Suarez et al., 2010; Huang and Gibb, 2014) since all NMDA sEPSCs were sensitive to Ro 25-6981, but not all were sensitive to DQP 1105 .

After P30, our results suggest that SNc neurons no longer express GluN2D-containing NMDA receptors, since NMDA sEPSCs were no longer either bursty or sensitive to DQP 1105. Transient expression of the GluN2D subunit mRNA and a peak of expression around $\mathrm{P} 7$ are features described in midbrain regions (Monyer et al., 1994; Dunah et al., 1996; Wenzel et al., 1996; Laurie et al., 1997; Liu and Wong-Riley, 2010), suggesting that GluN2D subunit-containing NMDA receptors play a role in these brain regions mainly during development (von Engelhardt et al., 2015). Consistent with these results, we demonstrate the dynamic remodeling of NMDA receptor subunit composition in SNc DA neurons during postnatal development with GluN2D subunits no longer present in young adult mice.

The key role of NMDAR-mediated currents at P4-P10 is also revealed by the large APV-sensitive (but DQP 1105insensitive) burst of spikes evoked by STN stimulation in immature but not in $\mathrm{P} 30+\mathrm{SNc} \mathrm{DA}$ neurons. The lack of effect of DQP 1105 might result from the absence of NR2D subunit-containing NMDAR in the postsynaptic membrane of STN-SNc synapses. It could also result from the low participation of these NMDAR subtypes to the depolarization underlying the STN-evoked burst of spikes compared to the current through NR2B subunit-containing NMDARs and voltage-dependent calcium channels. Interestingly, a similar

\section{References}

Acker, T. M., Yuan, H., Hansen, K. B., Vance, K. M., Ogden, K. K., Jensen, H. S., et al. (2011). Mechanism for noncompetitive inhibition by novel GluN2C/D N-methyl-D-aspartate receptor subunit-selective modulators. Mol. Pharmacol. 80, 782-795. doi: 10.1124/mol.111. 073239

Bischoff, S., Barhanin, J., Bettler, B., Mulle, C., and Heinemann, S. (1997). Spatial distribution of kainate receptor subunit mRNA in the mouse basal ganglia and ventral mesencephalon. J. Comp. Neurol. 379, 541-562. doi: 10.1002/(SICI)1096-9861(19970324)379:4<541::AID-CNE6>3.0.CO;2-2

Blythe, S. N., Atherton, J. F., and Bevan, M. D. (2007). Synaptic activation of dendritic AMPA and NMDA receptors generates transient high-frequency firing in substantia nigra dopamine neurons in vitro. J. Neurophysiol. 97, 2837-2850. doi: 10.1152/jn.01157.2006

Blythe, S. N., Wokosin, D., Atherton, J. F., and Bevan, M. D. (2009). Cellular mechanisms underlying burst firing in substantia nigra dopamine neurons. J. Neurosci. 29, 15531-15541. doi: 10.1523/JNEUROSCI.296109.2009

Brothwell, S. L., Barber, J. L., Monaghan, D. T., Jane, D. E., Gibb, A. J., and Jones, S. (2008). NR2B- and NR2D-containing synaptic NMDA receptors in developing
NMDAR-dependent burst was described in the SNc of P14P21 mice (Hage and Khaliq, 2015), suggesting that NMDA EPSCs mature after P21 and before P30. This large P4P10 STN-evoked burst of spikes did not result from a different basal tonic firing rate before the stimulation which tunes synaptic gain in SNc DA neurons (Hage and Khaliq, 2015). During the burst, the progressive increase in the depolarization underlying the burst of spikes might result from backpropagation in the dendrites of the first spikes in the burst. These backpropagated spikes, by increasing calcium influx in dendrites, amplify the amplitude of NMDA EPSPs evoked by STN stimulation (Hage and Khaliq, 2015).

\section{Author Contributions}

EP, LAGC, FM, and RC performed the experiments. EP, LAGC, $\mathrm{FM}$, and $\mathrm{CH}$ analyzed the data. $\mathrm{CH}$ designed the study and wrote the paper.

\section{Acknowledgment}

The authors acknowledge the support of the animal house facility headed by S. Pellegrino.

\section{Supplementary Material}

The Supplementary Material for this article can be found online at: http://journal.frontiersin.org/article/10.3389/fncel. 2015.00210/abstract

Figure S1 | Representative confocal image of the SNc (coronal section) from a TH-GFP mouse showing TH-positive neurons labeled with Alexa A555 (left), GFP positive neurons (right) and merged image (center). Arrows show GFP-positive/TH-negative SNc neurons. Scale bar $50 \mu \mathrm{m}$.

rat substantia nigra pars compacta dopaminergic neurones. J. Physiol. 586, 739-750. doi: 10.1113/jphysiol.2007.144618

Bunney, B. S., Aghajanian, G. K., and Roth, R. H. (1973). Comparison of effects of L-dopa, amphetamine and apomorphine on firing rate of rat dopaminergic neurones. Nat. New Biol. 245, 123-125. doi: 10.1038/newbio245123a0

Calabresi, P., Picconi, B., Tozzi, A., and Di Filippo, M. (2007). Dopamine-mediated regulation of corticostriatal synaptic plasticity. Trends Neurosci. 30, 211-219. doi: 10.1016/j.tins.2007.03.001

Centonze, D., Picconi, B., Gubellini, P., Bernardi, G., and Calabresi, P. (2001). Dopaminergic control of synaptic plasticity in the dorsal striatum. Eur. J. Neurosci. 13, 1071-1077. doi: 10.1046/j.0953-816x.2001. 01485.x

Chatha, B. T., Bernard, V., Streit, P., and Bolam, J. P. (2000). Synaptic localization of ionotropic glutamate receptors in the rat substantia nigra. Neuroscience 101, 1037-1051. doi: 10.1016/S0306-4522(00)00432-2

Chergui, K., Akaoka, H., Charlety, P. J., Saunier, C. F., Buda, M., and Chouvet, G. (1994). Subthalamic nucleus modulates burst firing of nigral dopamine neurones via NMDA receptors. Neuroreport 5, 1185-1188. doi: 10.1097/00001756-199406020-00006

Chergui, K., Charlety, P. J., Akaoka, H., Saunier, C. F., Brunet, J. L., Buda, M., et al. (1993). Tonic activation of NMDA receptors causes 
spontaneous burst discharge of rat midbrain dopamine neurons in vivo. Eur. J. Neurosci. 5, 137-144. doi: 10.1111/j.1460-9568.1993. tb00479.x

Christoffersen, C. L., and Meltzer, L. T. (1995). Evidence for N-methyl-Daspartate and AMPA subtypes of the glutamate receptor on substantia nigra dopamine neurons: possible preferential role for N-methyl-D-aspartate receptors. Neuroscience 67, 373-381. doi: 10.1016/0306-4522(95)00047-M

Counihan, T. J., Landwehrmeyer, G. B., Standaert, D. G., Kosinski, C. M., Scherzer, C. R., Daggett, L. P., et al. (1998). Expression of N-methylD-aspartate receptor subunit mRNA in the human brain: mesencephalic dopaminergic neurons. J. Comp. Neurol. 390, 91-101. doi: 10.1002/(SICI)10969861(19980105)390:1<91::AID-CNE8>3.0.CO;2-L

Deister, C. A., Teagarden, M. A., Wilson, C. J., and Paladini, C. A. (2009). An intrinsic neuronal oscillator underlies dopaminergic neuron bursting. J. Neurosci. 29, 15888-15897. doi: 10.1523/JNEUROSCI.4053-09.2009

Dunah, A. W., Luo, J., Wang, Y. H., Yasuda, R. P., and Wolfe, B. B. (1998). Subunit composition of N-methyl-D-aspartate receptors in the central nervous system that contain the NR2D subunit. Mol. Pharmacol. 53, 429-437.

Dunah, A. W., Yasuda, R. P., Wang, Y. H., Luo, J., Davila-Garcia, M., Gbadegesin, M., et al. (1996). Regional and ontogenic expression of the NMDA receptor subunit NR2D protein in rat brain using a subunit-specific antibody. J. Neurochem. 67, 2335-2345. doi: 10.1046/j.1471-4159.1996.6706 2335.x

Fa, M., Mereu, G., Ghiglieri, V., Meloni, A., Salis, P., and Gessa, G. L. (2003). Electrophysiological and pharmacological characteristics of nigral dopaminergic neurons in the conscious, head-restrained rat. Synapse 48, 1-9. doi: $10.1002 /$ syn.10177

Falkenburger, B. H., Barstow, K. L., and Mintz, I. M. (2001). Dendrodendritic inhibition through reversal of dopamine transport. Science 293, 2465-2470. doi: 10.1126/science. 1060645

Ferrari, D. C., Mdzomba, B. J., Dehorter, N., Lopez, C., Michel, F. J., Libersat, F., et al. (2012). Midbrain dopaminergic neurons generate calcium and sodium currents and release dopamine in the striatum of pups. Front. Cell. Neurosci. 6:7. doi: 10.3389/fncel.2012.00007

Futami, T., Takakusaki, K., and Kitai, S. T. (1995). Glutamatergic and cholinergic inputs from the pedunculopontine tegmental nucleus to dopamine neurons in the substantia nigra pars compacta. Neurosci. Res. 21, 331-342. doi: 10.1016/0168-0102(94)00869-H

Gentet, L. J., and Williams, S. R. (2007). Dopamine gates action potential backpropagation in midbrain dopaminergic neurons. J. Neurosci. 27, 18921901. doi: 10.1523/JNEUROSCI.5234-06.2007

Gonon, F. G. (1988). Nonlinear relationship between impulse flow and dopamine released by rat midbrain dopaminergic neurons as studied by in vivo electrochemistry. Neuroscience 24, 19-28. doi: 10.1016/0306-4522(88)90307-7

Gotz, T., Kraushaar, U., Geiger, J., Lubke, J., Berger, T., and Jonas, P. (1997). Functional properties of AMPA and NMDA receptors expressed in identified types of basal ganglia neurons. J. Neurosci. 17, 204-215.

Grace, A. A., and Bunney, B. S. (1983). Intracellular and extracellular electrophysiology of nigral dopaminergic neurons-2. Action potential generating mechanisms and morphological correlates. Neuroscience 10, 317-331. doi: 10.1016/0306-4522(83)90136-7

Grace, A. A., and Bunney, B. S. (1984a). The control of firing pattern in nigral dopamine neurons: burst firing. J. Neurosci. 4, 2877-2890.

Grace, A. A., and Bunney, B. S. (1984b). The control of firing pattern in nigral dopamine neurons: single spike firing. J. Neurosci. 4, 2866-2876.

Grace, A. A., and Onn, S. P. (1989). Morphology and electrophysiological properties of immunocytochemically identified rat dopamine neurons recorded in vitro. J. Neurosci. 9, 3463-3481.

Grillner, P., and Mercuri, N. B. (2002). Intrinsic membrane properties and synaptic inputs regulating the firing activity of the dopamine neurons. Behav. Brain Res. 130, 149-169. doi: 10.1016/S0166-4328(01)00418-1

Gulacsi, A., Lee, C. R., Sik, A., Viitanen, T., Kaila, K., Tepper, J. M., et al. (2003). Cell type-specific differences in chloride-regulatory mechanisms and GABA(A) receptor-mediated inhibition in rat substantia nigra. J. Neurosci. 23, 8237-8246.

Hage, T. A., and Khaliq, Z. M. (2015). Tonic firing rate controls dendritic $\mathrm{Ca}^{2+}$ signaling and synaptic gain in substantia nigra dopamine neurons. J. Neurosci. 35, 5823-5836. doi: 10.1523/JNEUROSCI.3904-14.2015
Hammond, C., Deniau, J. M., Rizk, A., and Féger, J. (1978). Electrophysiological demonstration of an excitatory subthalamonigral pathway in the rat. Brain Res. 151, 235-244. doi: 10.1016/0006-8993(78)90881-8

Hausser, M., Stuart, G., Racca, C., and Sakmann, B. (1995). Axonal initiation and active dendritic propagation of action potentials in substantia nigra neurons. Neuron 15, 637-647. doi: 10.1016/0896-6273(95) 90152-3

Huang, Z., and Gibb, A. J. (2014). $\mathrm{Mg}^{2+}$ block properties of triheteromeric GluN1-GluN2B-GluN2D NMDA receptors on neonatal rat substantia nigra pars compacta dopaminergic neurones. J. Physiol. 592, 2059-2078. doi: 10.1113/jphysiol.2013.267864

Hyland, B. I., Reynolds, J. N., Hay, J., Perk, C. G., and Miller, R. (2002). Firing modes of midbrain dopamine cells in the freely moving rat. Neuroscience 114, 475-492. doi: 10.1016/S0306-4522(02)00267-1

Jackson, A., and Crossman, A. R. (1983). Nucleus tegmenti pedunculopontinus: efferent connections with special reference to the basal ganglia, studied in the rat by anterograde and retrograde transport of horseradish peroxidase. Neuroscience 10, 725-765. doi: 10.1016/0306-4522(83)90213-0

Johnson, S. W., Seutin, V., and North, R. A. (1992). Burst firing in dopamine neurons induced by N-methyl-D-aspartate: role of electrogenic sodium pump. Science 258, 665-667. doi: 10.1126/science.1329209

Jones, S., and Gibb, A. J. (2005). Functional NR2B- and NR2D-containing NMDA receptor channels in rat substantia nigra dopaminergic neurons. J. Physiol. 569, 209-221. doi: 10.1113/jphysiol.2005.095554

Kreitzer, A. C., and Malenka, R. C. (2008). Striatal plasticity and basal ganglia circuit function. Neuron 60, 543-554. doi: 10.1016/j.neuron.2008.11.005

Laurie, D. J., Schoeffter, P., Wiederhold, K. H., and Sommer, B. (1997). Cloning, distribution and functional expression of the human mGlu6 metabotropic glutamate receptor. Neuropharmacology 36, 145-152. doi: 10.1016/S00283908(96)00172-4

Lin, J. Y., and Lipski, J. (2001). Dopaminergic substantia nigra neurons express functional nmda receptors in postnatal rats. J. Neurophysiol. 85, 1336-1339.

Liu, Q., and Wong-Riley, M. T. (2010). Postnatal development of N-methylD-aspartate receptor subunits $2 \mathrm{~A}, 2 \mathrm{~B}, 2 \mathrm{C}, 2 \mathrm{D}$, and $3 \mathrm{~B}$ immunoreactivity in brain stem respiratory nuclei of the rat. Neuroscience 171, 637-654. doi: 10.1016/j.neuroscience.2010.09.055

Manley, L. D., Kuczenski, R., Segal, D. S., Young, S. J., and Groves, P. M. (1992). Effects of frequency and pattern of medial forebrain bundle stimulation on caudate dialysate dopamine and serotonin. J. Neurochem. 58, 1491-1498. doi: 10.1111/j.1471-4159.1992.tb11369.x

Matsushita, N., Okada, H., Yasoshima, Y., Takahashi, K., Kiuchi, K., and Kobayashi, K. (2002). Dynamics of tyrosine hydroxylase promoter activity during midbrain dopaminergic neuron development. J. Neurochem. 82, 295304. doi: 10.1046/j.1471-4159.2002.00972.x

Meltzer, L. T., Christoffersen, C. L., and Serpa, K. A. (1997). Modulation of dopamine neuronal activity by glutamate receptor subtypes. Neurosci. Biobehav. Rev. 21, 511-518. doi: 10.1016/S0149-7634(96)00030-9

Mereu, G., Costa, E., Armstrong, D. M., and Vicini, S. (1991). Glutamate receptor subtypes mediate excitatory synaptic currents of dopamine neurons in midbrain slices. J. Neurosci. 11, 1359-1366.

Mereu, G., Lilliu, V., Casula, A., Vargiu, P. F., Diana, M., Musa, A., et al. (1997). Spontaneous bursting activity of dopaminergic neurons in midbrain slices from immature rats: role of N-methyl-D-aspartate receptors. Neuroscience 77, 1029-1036. doi: 10.1016/S0306-4522(96)00474-5

Monyer, H., Burnashev, N., Laurie, D. J., Sakmann, B., and Seeburg, P. H. (1994). Developmental and regional expression in the rat brain and functional properties of four NMDA receptors. Neuron 12, 529-540. doi: 10.1016/08966273(94)90210-0

Paladini, C. A., and Roeper, J. (2014). Generating bursts (and pauses) in the dopamine midbrain neurons. Neuroscience 282C, 109-121. doi: 10.1016/j.neuroscience.2014.07.032

Park, M., Kitahama, K., Geffard, M., and Maeda, T. (2000). Postnatal development of the dopaminergic neurons in the rat mesencephalon. Brain Dev. 22(Suppl. 1), S38-S44. doi: 10.1016/S0387-7604(00)00145-5

Reynolds, J. N., and Wickens, J. R. (2000). Substantia nigra dopamine regulates synaptic plasticity and membrane potential fluctuations in the rat neostriatum, in vivo. Neuroscience 99, 199-203. doi: 10.1016/S0306-4522(00) 00273-6 
Richards, C. D., Shiroyama, T., and Kitai, S. T. (1997). Electrophysiological and immunocytochemical characterization of GABA and dopamine neurons in the substantia nigra of the rat. Neuroscience 80, 545-557. doi: 10.1016/S03064522(97)00093-6

Rinvik, E., and Ottersen, O. P. (1993). Terminals of subthalamonigral fibres are enriched with glutamate-like immunoreactivity: an electron microscopic, immunogold analysis in the cat. J. Chem. Neuroanat. 6, 19-30. doi: 10.1016/0891-0618(93)90004-N

Rye, D. B., Saper, C. B., Lee, H. J., and Wainer, B. H. (1987). Pedunculopontine tegmental nucleus of the rat: cytoarchitecture, cytochemistry, and some extrapyramidal connections of the mesopontine tegmentum. J. Comp. Neurol. 259, 483-528. doi: 10.1002/cne.902590403

Scarnati, E., Campana, E., and Pacitti, C. (1984). Pedunculopontine-evoked excitation of substantia nigra neurons in the rat. Brain Res. 304, 351-361. doi: 10.1016/0006-8993(84)90339-1

Schultz, W. (2013). Updating dopamine reward signals. Curr. Opin. Neurobiol. 23, 229-238. doi: 10.1016/j.conb.2012.11.012

Smith, I. D., and Grace, A. A. (1992). Role of the subthalamic nucleus in the regulation of nigral dopamine neuron activity. Synapse 12, 287-303. doi: 10.1002/syn.890120406

Suarez, F., Zhao, Q., Monaghan, D. T., Jane, D. E., Jones, S., and Gibb, A. J. (2010). Functional heterogeneity of NMDA receptors in rat substantia nigra pars compacta and reticulata neurones. Eur. J. Neurosci. 32, 359-367. doi: 10.1111/j.1460-9568.2010.07298.x

Takakusaki, K., Shiroyama, T., Yamamoto, T., and Kitai, S. T. (1996). Cholinergic and noncholinergic tegmental pedunculopontine projection neurons in rats revealed by intracellular labeling. J. Comp. Neurol. 371, 345-361. doi: 10.1002/(SICI)1096-9861(19960729)371:3<345::AID-CNE1>3.0.CO;2-2

Tepper, J. M., Damlama, M., and Trent, F. (1994). Postnatal changes in the distribution and morphology of rat substantia nigra dopaminergic neurons. Neuroscience 60, 469-477. doi: 10.1016/0306-4522(94)90258-5

Vicini, S., Wang, J. F., Li, J. H., Zhu, W. J., Wang, Y. H., Luo, J. H., et al. (1998). Functional and pharmacological differences between recombinant N-methylD-aspartate receptors. J. Neurophysiol. 79, 555-566.

Vivo, M., Camon, L., de, V. N., and Martinez, E. (2002). Lesion of substantia nigra pars compacta by the GluR5 agonist ATPA. Brain Res. 955, 104-114. doi: 10.1016/S0006-8993(02)03373-5

von Engelhardt, E. J., Bocklisch, C., Tonges, L., Herb, A., Mishina, M., and Monyer, H. (2015). GluN2D-containing NMDA receptors-mediate synaptic currents in hippocampal interneurons and pyramidal cells in juvenile mice. Front. Cell. Neurosci. 9:95. doi: 10.3389/fncel.2015.00095

Wang, L. P., Li, F., Wang, D., Xie, K., Wang, D., Shen, X., et al. (2011). NMDA receptors in dopaminergic neurons are crucial for habit learning. Neuron 72 , 1055-1066. doi: 10.1016/j.neuron.2011.10.019
Wenzel, A., Villa, M., Mohler, H., and Benke, D. (1996). Developmental and regional expression of NMDA receptor subtypes containing the NR2D subunit in rat brain. J. Neurochem. 66, 1240-1248. doi: 10.1046/j.14714159.1996.66031240.x

Wise, R. A. (2004). Dopamine, learning and motivation. Nat. Rev. Neurosci. 5, 483-494. doi: 10.1038/nrn1406

Wullner, U., Standaert, D. G., Testa, C. M., Penney, J. B., and Young, A. B. (1997). Differential expression of kainate receptors in the basal ganglia of the developing and adult rat brain. Brain Res. 768, 215-223. doi: 10.1016/S00068993(97)00645-8

Wyllie, D. J., Behe, P., and Colquhoun, D. (1998). Single-channel activations and concentration jumps: comparison of recombinant NR1a/NR2A and NR1a/NR2D NMDA receptors. J. Physiol. 510(Pt 1), 1-18. doi: 10.1111/j.14697793.1998.001bz.x

Yamaguchi, T., Sheen, W., and Morales, M. (2007). Glutamatergic neurons are present in the rat ventral tegmental area. Eur. J. Neurosci. 25, 106-118. doi: 10.1111/j.1460-9568.2006.05263.x

Yamaguchi, T., Wang, H. L., Li, X., Ng, T. H., and Morales, M. (2011). Mesocorticolimbic glutamatergic pathway. J. Neurosci. 31, 8476-8490. doi: 10.1523/JNEUROSCI.1598-11.2011

Yamaguchi, T., Wang, H. L., and Morales, M. (2013). Glutamate neurons in the substantia nigra compacta and retrorubral field. Eur. J. Neurosci. 38, 3602-3610. doi: 10.1111/ejn.12359

Yung, W. H., Hausser, M. A., and Jack, J. J. (1991). Electrophysiology of dopaminergic and non-dopaminergic neurones of the guinea-pig substantia nigra pars compacta in vitro. J. Physiol. 436, 643-667. doi: 10.1113/jphysiol.1991.sp018571

Zweifel, L. S., Parker, J. G., Lobb, C. J., Rainwater, A., Wall, V. Z., Fadok, J. P., et al. (2009). Disruption of NMDAR-dependent burst firing by dopamine neurons provides selective assessment of phasic dopamine-dependent behavior. Proc. Natl. Acad. Sci. U.S.A. 106, 7281-7288. doi: 10.1073/pnas.08134 15106

Conflict of Interest Statement: The authors declare that the research was conducted in the absence of any commercial or financial relationships that could be construed as a potential conflict of interest.

Copyright (c) 2015 Pearlstein, Gouty-Colomer, Michel, Cloarec and Hammond. This is an open-access article distributed under the terms of the Creative Commons Attribution License (CC BY). The use, distribution or reproduction in other forums is permitted, provided the original author(s) or licensor are credited and that the original publication in this journal is cited, in accordance with accepted academic practice. No use, distribution or reproduction is permitted which does not comply with these terms. 